\title{
Sykepleiere trenger kompetanse i samvalg
}

Sykepleiere bør få ansvaret for samvalgsveiledning av pasienter i samarbeid med leger. Det vil hjelpe pasientene med å ta beslutninger om behandling.

\section{Simone Kienlin}

Sykepleier, stipendiat og spesialrådgiver

Universitetssykehuset Nord-Norge, UiT - Norges arktiske universitet og Samvalg Helse

Sør-Øst

Mirjam Smedsrød

Sykepleier

Fagavdelingen og samhandlingsenheten, Sørlandet sykehus

Hilde Eide

Sykepleier og professor

Vitensenteret helse og teknologi, Fakultet for helse- og sosialvitenskap, Universitetet i

Sørøst-Norge

Jürgen Kasper

Professor

Institutt for sykepleie og helsefremmende arbeid, Fakultet for helsevitenskap, Oslomet storbyuniversitetet

Samvalg

$$
\text { Kommunikasjon }
$$

Brukermedvirkning

\section{Hovedbudskap}


Sykepleiere må i større grad bidra til å øke kvaliteten på beslutninger som angår pasientens helse. Samvalg skal være det normale i helsetjenesten, og sykepleiere bør derfor få muligheten til å tilegne seg ny kunnskap og utvikle nye ferdigheter. Både i grunnog videreutdanninger samt i spesialist- og primærhelsetjenesten må vi legge vekt på å utvikle sykepleiernes samvalgskompetanse.

Tenk på en av dine pasienter som står overfor en krevende beslutning mellom flere behandlinger. Ulike konsekvenser følger med alternativene. Hvordan vil du identifisere pasientens behov, og hvordan vil du veilede og st $\varnothing t t e$ pasienten?

Hverdagen er full av situasjoner der mennesker står foran helserelaterte valg mellom ulike alternativer. Mennesker har alltid gjort og forsvart sine valg, som for eksempel egne kostog aktivitetsvaner.

Av ulike grunner finnes det mange valg som blir tatt av eller sammen med helsepersonell, som for eksempel valg av fremgangsmåte ved utredning eller behandling ved sykdom. Det ligger til legerollen å være beslutningstaker, men det finnes også mange beslutninger som tradisjonelt ligger innenfor sykepleierens ansvarsområde.

\section{Rollene endrer seg}

Ansvarsdelingen i helserelaterte beslutninger er under utvikling. Målet om «pasientens helsetjeneste» innebærer radikale endringer i den forstand at tradisjonelle roller endres. Denne utviklingen kan forstås som en kulturendring som foregår på to nivåer: mellom helsepersonellet og pasienten, og mellom helsepersonellet.

Tidligere var relasjonen mellom pasienten og helsepersonellet mer preget av pasientens tiltro til at «legen vet best». I dag ønsker pasientene heller å vite enn å tro, og de vil være aktive fremfor passive (1).

Noen personer har mer kunnskap om sin egen helse, mens andre vet mer om hva de kan forvente som bruker av helsetjenestene. Mange har evnen til å forstå det faglige knyttet til sykdommen sin og valgene de må ta. Det er derfor forventet at dagens pasienter involveres og får en mer aktiv rolle. 
Over tid har det skjedd en oppgaveglidning mellom leger og sykepleiere, der sykepleiere i dag gjør mer avanserte oppgaver som tidligere var legeoppgaver. Dagens sykepleier har høyere kompetanse, er ofte spesialisert og făr i økende grad en rolle i beslutninger som tidligere kun ble tatt mellom legen og pasienten (tabell 1).

Kunnskapsbasert praksis medfører at beslutningstaking om omsorg og behandling både blir mer kompleks og mer systematisk. Med disse endringene får rollene til alle parter en dreining, og en ny oppgavefordeling må etableres.

Tabell 1. Eksempler på beslutninger som er aktuelle for samvalg veiledet av sykepleieren

\begin{tabular}{|c|c|c|}
\hline Fagområde & Type valg & Valgalternativer \\
\hline Egenbehandling diabetes & $\begin{array}{l}\text { Hvordan regulere } \\
\text { blodsukker }\end{array}$ & For eksempel penn eller pumpe \\
\hline Unngå graviditet & Prevensjonsmetode & $\begin{array}{l}\text { Ikke-hormonelle prevensjonsmidler, livmorinnlegg } \\
\text { eller barrieremetoder }\end{array}$ \\
\hline Livets sluttfase & $\begin{array}{l}\text { Hvor sluttfasen av livet } \\
\text { tilbringes }\end{array}$ & Hjemmed $\varnothing d$, hospice eller sykehjem/sykehus \\
\hline Barselkvinnen & Ernæring av nyfødt & Amming eller flaske \\
\hline Brystkreft i tidlig stadium & Type kirurgi & $\begin{array}{l}\text { Brystbevarende kirurgi etterfulgt av strålebehandling, } \\
\text { fjerne hele brystet med eller uten samtidig rekonstruksjon }\end{array}$ \\
\hline $\begin{array}{l}\text { Degenerativ nevrologisk } \\
\text { sykdom, for eksempel ALS }\end{array}$ & $\begin{array}{l}\text { Valg av behandlings- } \\
\text { hjelpemidler }\end{array}$ & Hjemmerespirator eller ikke \\
\hline
\end{tabular}

\section{Definisjon av «samvalg»}

Samvalg (shared decision-making) (2) er en metode for hvordan kommunikasjon mellom helsepersonellet og pasienten kan struktureres når det skal tas medisinske og helserelaterte beslutninger for å komme frem til et informert $\operatorname{valg}(3,4)$.

I Nasjonal helse- og sykehusplan (2016-2019) står følgende: «Ved samvalg samarbeider pasient og helsepersonell om å treffe beslutninger om utredning, behandling og oppfølging, i den grad og på de måter pasienten ønsker. Pasienten får støtte til å vurdere alternativene, ut fra beste tilgjengelige kunnskap om fordeler og ulemper, og til å utforske egne verdier og preferanser.» (4, s. 61)

\section{Sykepleiere er godt forberedt}

Pasientdeltakelse har alltid vært sentralt i sykepleierens arbeid rundt pasienten, og ingen profesjon eller yrkesgruppe er i dag bedre forberedt på å møte nye krav og forventninger om å involvere pasientene aktivt i tjenestene. 
Deltakelse handler ikke om pasienters etterlevelse og lydighet, men først og fremst om myndige og aktive brukere av helsetjenester. Poenget er at pasientene selv må bestemme på hvilke måter og i hvilken grad de ønsker å samhandle med helsepersonellet. En forutsetning for slik samhandling er god pasientinformasjon, som tradisjonelt er en viktig oppgave for sykepleierne.

Med samvalg som en del av en ny kommunikasjonskultur følger også kriterier for hvilken informasjon som kreves, og for hvordan den utformes og formidles, da dette er avgjørende for pasientenes og de pårørendes mulighet til å forstå, kritisk vurdere og anvende helseinformasjonen (5).

\section{三 «Nøkkelen til å lykkes i en slik prosess er en godt etablert relasjon.»}

For noen vil det innebære at formen på informasjonen som gis, blir tilpasset ved å følge kriterier for kunnskapsbasert pasientinformasjon, som har som mål å øke kvaliteten på helseinformasjonen (5).

Ved siden av pasientinformasjon er kartlegging av pasientens individuelle behov, verdier og preferanser noe av det mest utfordrende i samvalg. Det kan være en vanskelig balansegang å ivareta pasientens autonomi ved å veilede pasienten i å få frem sine egne preferanser uten å synliggjøre sykepleierens eget ståsted.

Nøkkelen til å lykkes i en slik prosess er en godt etablert relasjon. Sykepleieren jobber tett på pasientene, og gjennom det relasjonelle arbeidet vil de ha god tilgang til pasientens perspektiv.

\section{Veiledning innebærer selvbestemmelse}

Selve samvalgsdialogen innebærer ikke rådgivning, instruksjon og anbefalinger, som fortsatt har sin berettigelse andre steder i konsultasjonen. Veiledning i samvalg legger til rette for at pasienten kan utvikle egen kompetanse og med høyest mulig grad av selvbestemmelse være delaktig i beslutninger om egen helse (6). 
Hva som skal være avgjørende for å identifisere samvalgsrelevante situasjoner, og hvem som kan avgjøre dette, er betydningsfullt når det gjelder å vurdere at tiden har kommet for å ta et valg. Mens legene er ansvarlige for utredninger, diagnostikk og behandlingsplaner, er det ofte sykepleierne som gjennomfører og ledsager behandlingen.

Sykepleierne er derfor ofte de første til å gjenkjenne når behandlinger bør justeres, revurderes eller avsluttes. Med dette bidrar sykepleieren til å identifisere beslutningsbehov som betinger et samvalg.

For å oppsummere er sykepleiere gjennom utdanning og tradisjonelle oppgaveområder godt forberedt til å ta ansvaret for å legge til rette for samvalg. Det samme gjelder for å gjennomføre samvalg.

Selv om samvalg, som internasjonalt har blitt fremmet i mer enn 20 år, ofte har blitt plassert i møtet mellom lege og pasient, er det en økende forståelse for at sykepleieren har en viktig rolle med å gjennomføre samvalgssamtaler og for metodikken dette innebærer.

Konseptuelle modeller om samvalg omtaler i senere tid oftere sykepleierens eksplisitte og nyttige rolle i samvalg (7-10). Pasientene selv utpeker sykepleieren som sin «helseadvokat» og ønsker at de i større grad deltar (11).

\section{Sykepleieren kan være samvalgsveileder}

Sykepleierens tradisjonelle rolleforståelse er både et godt utgangspunkt for og har stort potensial til å stimulere til samvalg og gi rom for at pasienten kan delta aktivt. Erfaring fra andre land (12) viser at det er svært usannsynlig at samvalg kan innføres uten en nasjonal, systematisk og kunnskapsbasert tilnærming (13).

Samvalg kan kun bli en troverdig tilnærming dersom den bygger på at alle yrkesgruppene har en felles forståelse av pasientens rolle, samt at de har en rollefordeling i det tverrfaglige samarbeidet rundt pasientinvolvering. Opplæringstiltak bør derfor rettes mot hele avdelinger med formålet om å skape en felles forståelse av at pasienten er i stand til å forstå medisinsk informasjon og aktivt delta i beslutninger (14).

En samvalgsveileder (decision coach) er helsepersonell som har fått opplæring i å veilede og støtte pasienter som står overfor en beslutning, til å oppnå et informert valg (6). 
I tillegg vil det være behov for at sykepleierne tilegner seg spisskompetanse innen samvalgsveiledning. En samvalgsveileder er kurset og sertifisert i en metode som er dokumentert effektiv i å støtte pasienter eller pårørende som skal fatte en beslutning.

Oppgavespekteret til samvalgsveilederen strekker seg fra å veilede pasienten i deler av beslutningsprosessen, som informasjonsformidling eller preferansekartlegging, til å gjennomføre en fullstendig samvalgsprosess.

Figur 1. Seks steg til samvalg

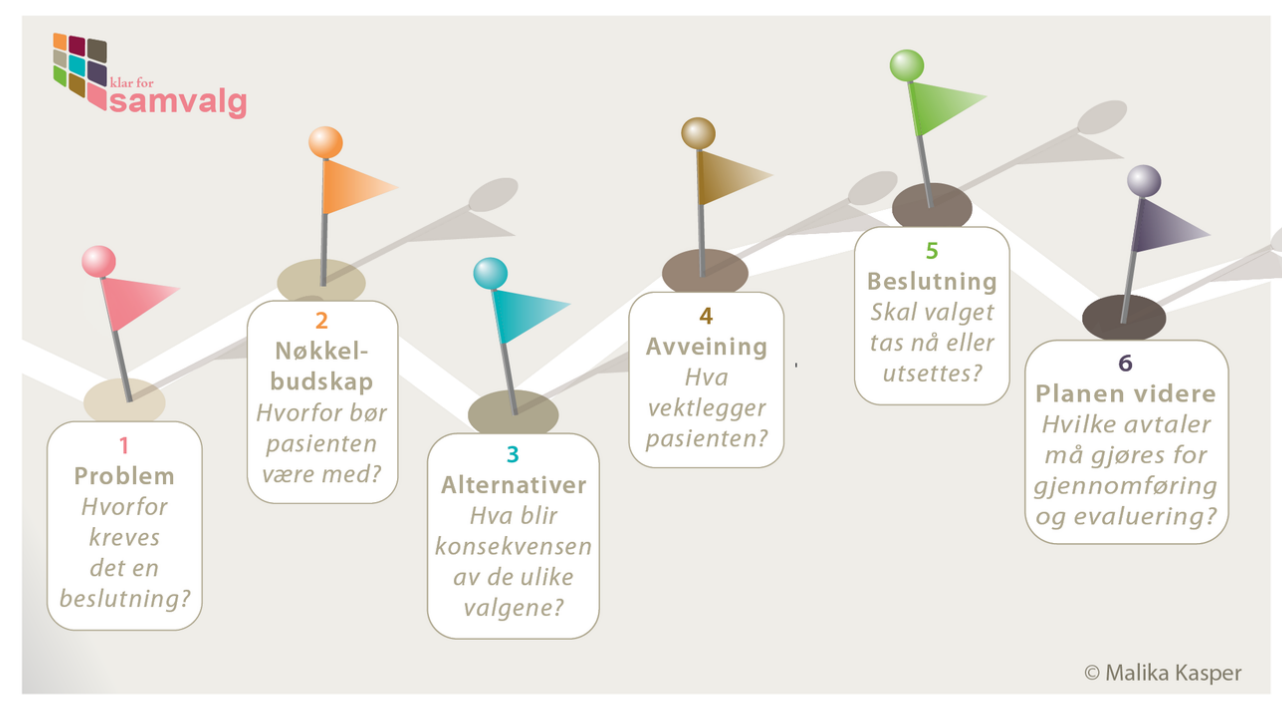

«Seks steg til samvalg» er en struktur for ideell gjennomføring av samvalg. Rekkefølgen på stegene har betydning, og hvert steg har gitte kriterier knyttet til informasjonsdeling og kommunikasjonen mellom pasienten og helsepersonellet. Illustrasjon: Helse Sør- $\varnothing$ st RHF «Klar for samvalg». Gjengitt med tillatelse.

\section{Samvalgsveilederen har ulike oppgaver}

Hvilke oppgaver en samvalgsveileder får ansvaret for i en samvalgsprosess, er først og fremst et spørsmål om hvilke(n) problemstilling(er) beslutningen gjelder.

Når en sykepleier er involvert i å gjennomføre et tiltak, for eksempel i forbindelse med smertebehandling, kan det være mer aktuelt at sykepleieren overtar en stor del av kommunikasjonen. Dette skiller seg for eksempel fra beslutninger om kirurgiske tiltak, der legen er den som gjennomfører behandlingen.

Vi erfarer at det er stor variasjon mellom medisinske fagområder når det gjelder hvor stort ansvar sykepleieren får i sammenheng med medisinsk beslutningstaking. Litteraturen viser også at det er stor variasjon på hvilke områder og $\mathrm{i}$ hvilke problemstillinger samvalg blir praktisert (15). 
Tilgangen samvalgsveilederen får til evaluerte

samvalgsverktøy eller skreddersydde opplæringskurs, vil også være avgjørende for hvilke oppgaver vedkommende får. Her

følger tre eksempler:

\section{Integrering av beslutningsst $\varnothing t t e$ til pasienter $\mathbf{i}$ grunnleggende sykepleierutdanning}

Ved universitetet i Ottawa i Canada er det utviklet en trinnvis prosess for å heve sykepleierstudentenes kompetanse i det å støtte pasienter til å fatte beslutninger (16). På grunnutdanningen, som er fordelt over fire år, lærer studentene følgende:

- Hva samvalg er samt hvordan beslutninger påvirkes av verdier.

- Identifisere sykepleierens rolle i det å støtte pasienter eller pårørende som skal ta beslutninger.

- Bruke ulike verktøy for å støtte beslutninger.

- Utvikle og vurdere ferdigheter i samvalgsveiledning.

\section{Samvalgsveiledning av kvinner med påvist forstadium til brystkreft (ductalt carcinoma in situ, DCIS)}

I et tysk forskningsprosjekt som inkluderte 16 sertifiserte brystkreftsentre, ble kvinner som hadde fått diagnosen DCIS, veiledet av en kreftsykepleier som hadde kompetanse i samvalgsveiledning (17).

I veiledningen ble kvinnene forberedt på valget mellom fire ulike behandlingsalternativer: mastektomi, brystbevarende kirurgi med eller uten etterfulgt stråling eller observasjon. Sykepleierne hadde fått kursing i samvalgsveiledning, der informasjonsformidling og preferansekartlegging var sentrale temaer.

Kontrollgruppen fikk vanlige samtaler med onkolog uten at kreftsykepleierne var koplet inn som samvalgsveileder mellom samtalene. Resultatene viste at legekonsultasjonene ble mye kortere i gruppen med samvalgsveiledning.

Kvaliteten på kommunikasjonen rundt behandlingsvalget ble vurdert av uavhengige observatører, som konkluderte med at samvalgsveiledning resulterte i mer pasientdeltakelse sammenliknet med pasienter som ikke fikk samvalgsveiledning. 
Halvparten av kvinnene i veiledningsgruppen tok et informert valg, mens ingen av de valgene som ble tatt i kontrollgruppen, oppfylte kriteriene for informerte valg.

\section{Samvalgsveileder kan bidra til implementering av samvalgsverkt $\varnothing \mathrm{y}$}

I Norge er det utviklet flere samvalgsverktøy (13, 18-20), som er publisert på helsenorge.no. DAfactory har laget en veileder for hvordan samvalgsverktøy kan utvikles og implementeres mens de utvikles. En strategi i dette arbeidet er «Klar for samvalg» (21-25) - et rammeverk for kompetanseutvikling i samvalg.

\section{$\equiv$ «Samvalgsveilederen lærer å kartlegge pasientens ståsted og behov.»}

Samvalgsveiledning er en av modulene, et seks timers kurs som bygger på internasjonalt dokumenterte metoder, og som for tiden blir evaluert flere steder i Norge.

Samvalgsveilederen lærer å kartlegge pasientens ståsted og behov før de sammen gjennomfører deler av eller hele samvalgssamtalen, enten med eller uten et samvalgsverktøy.

Innen rammeverket «Klar for samvalg» er det også utviklet flere andre opplæringsmoduler som adresserer ulike profesjoner. Opplæring i samvalg kan dermed skreddersys til målgruppens behov. Formålet med å styrke kompetansen i samvalg er at flere pasienter får tatt informerte valg, og at kvaliteten på samvalgssamtaler øker.

Det er etablert et «Læringsnettverk for samvalg» med såkalte samvalgsambassadører som medlemmer. Disse er fagpersoner som har gjennomført «train-the-trainer-kurs» og er sertifisert til å gjennomføre opplæring i samvalg. Læringsnettverket bidrar også med å forbedre kvaliteten på opplæringsmodulene og implementere samvalg i klinikken (26). 


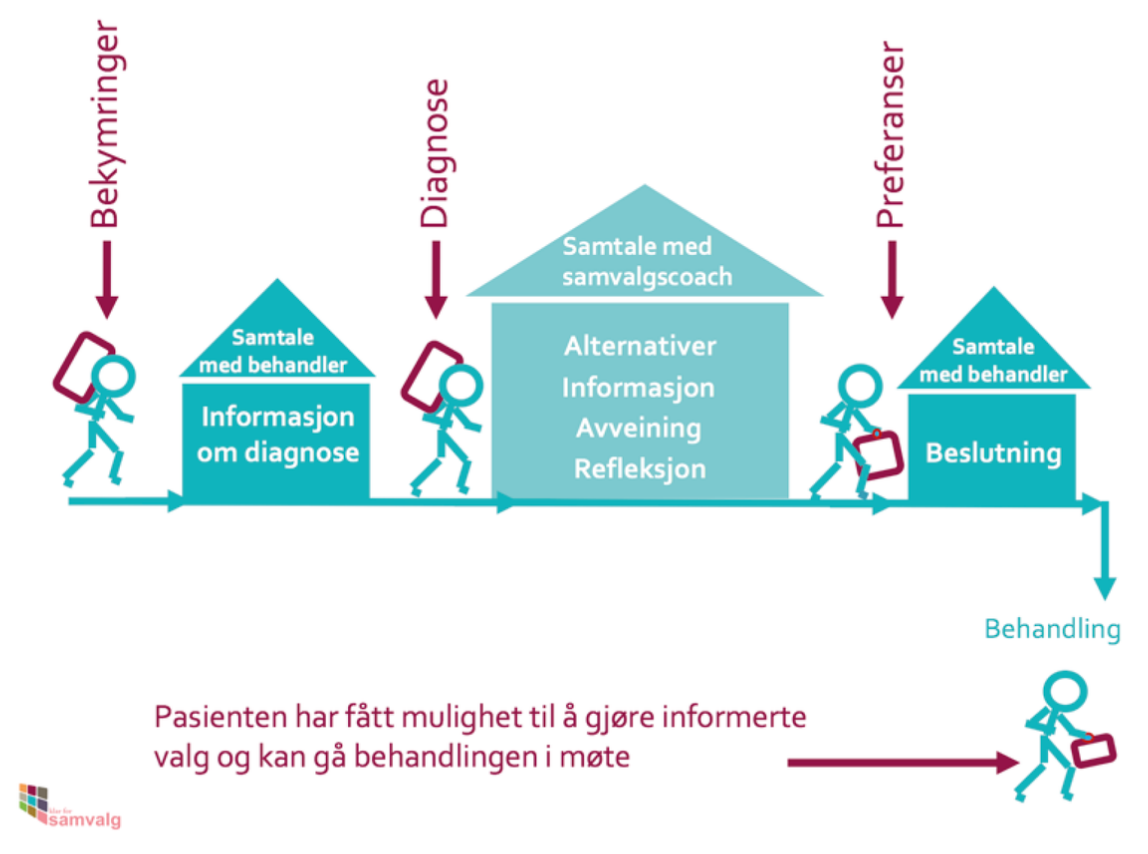

Rammeverket for kompetanseheving i samvalg.

Illustrasjon: Helse Sør- $\varnothing$ st RHF «Klar for samvalg». Gjengitt med tillatelse.

\section{Hva er status i Norge?}

Rettslige og politiske føringer i Norge er ikke til å misforstå og krever klart at helsepersonell skal legge til rette for at pasienten kan være med i valg som berører deres helse. Denne føringen er blant annet forankret i pasient- og brukerrettighetsloven (27) og i flere stortingsmeldinger (3, 27-31).

\section{$\equiv$ «Samvalg er også på vei inn i nye retningslinjer for utdanninger.»}

Samvalg er også på vei inn i nye retningslinjer for utdanninger, for eksempel i de (nye) nasjonale retningslinjene for helse- og sosialfagutdanningene, der samvalg skal få større plass i sykepleierutdanningen (32).

I lys av dette har vi muligens bedre forutsetninger for å innføre samvalg, enn de fleste andre land, og systembarrierer mot implementering virker lavere og overkommelige $(12,13)$.

\section{Oppsummering}


Pasientens rolle er i ferd med å endres. Pasienter blir mer aktive, og flere $\varnothing$ nsker å delta i beslutninger om egen helse. Dette paradigmeskiftet vil også påvirke sykepleiernes

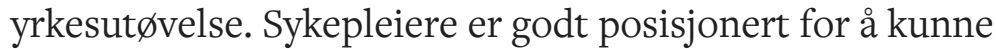
veilede pasienter i beslutninger, men har ofte behov for mer kunnskap og ferdigheter for å kunne gjennomføre en beslutningsprosess på best mulig måte (figur 2).

Mange pasienter $\varnothing$ nsker at sykepleieren deltar aktivt i samtaler om samvalg. Årsaken er at sykepleiere ofte tilbringer mye tid med pasienten og dermed kan være tilgjengelig for dialog med pasienten. Vi mener tiden er inne til at sykepleieren får ansvaret for samvalgsveiledning av pasienter i samarbeid med leger for å respondere på pasientenes $\varnothing$ nsker om og behov for å kunne delta mer i beslutninger.

Behovet underbygges av forskning som viser at beslutningsprosesser som er st $\varnothing$ ttet av kursede sykepleiere i form av en samvalgsveileder, blant annet fører til at pasienten får mer kunnskap og deltar mer i beslutninger $(8,9)$.

\section{三 «Mange pasienter $\emptyset$ nsker at sykepleieren deltar aktivt i samtaler om samvalg.»}

Samvalgsveiledning kan dessuten bidra til at helsearbeidere og pasienter kommer over barrierer når de skal innføre samvalg, for eksempel barrierer som maktubalansen mellom leger og pasienter og legenes tidsbegrensninger (11).

For å lykkes med å implementere samvalgsveiledning i helsevesenet må sykepleiere få muligheten til å tilegne seg ny kunnskap og utvikle nye ferdigheter. Kompetansen i samvalgsveiledning må styrkes i grunn- og videreutdanningen samt i helse- og omsorgstjenesten. Dette vil kunne bidra til at sykepleiere i fremtiden i enda større grad kan bidra til å $\varnothing \mathrm{ke}$ kvaliteten på beslutninger om pasientenes helse.

\section{Referanser}

1. Chewning B, Bylund CL, Shah B, Arora NK, Gueguen JA, Makoul G. Patient preferences for shared decisions: a systematic review. Patient Educ Couns. 2012;86(1):9-18.

2. Nylenna M. Om samvalg og andre sam-ord. Tidsskrift for Den norske legeforening. 2015;135(2):149. 
3. Charles C, Gafni A, Whelan T. Shared decision-making in the medical encounter: What does it mean? (Or it takes at least two to tango). Soc Sci Med. 1997;44(5):681-92.

4. Meld. St. 11 (2015-2016). Nasjonal helse- og sykehusplan (2016-2019). Oslo: Helse- og omsorgsdepartementet; 2015.

5. Lühnen J, Albrecht M, Mühlhauser I, Steckelberg A. Leitlinie evidenzbasierte Gesundheitsinformation. Hamburg: Universität Hamburg; 2017.

6. Jull J, Köpke S, Boland L, Coulter A, Dunn S, Graham I, et al. Decision coaching for people making healthcare decisions. Cochrane Database of Syst Rev. 2019;(7):CD013385.

7. Légaré F, Stacey D, Gagnon S, Dunn S, Pluye P, Frosch D, et al. Validating a conceptual model for an interprofessional approach to shared decision making: a mixed methods study. Journal of evaluation in clinical practice. 2011;17(4):554-64.

8. Stacey D, Kryworuchko J, Bennett C, Murray MA, Mullan S, Legare F. Decision coaching to prepare patients for making health decisions: a systematic review of decision coaching in trials of patient decision aids. Med Decis Making. 2012;32(3):E22-E33.

9. O'Connor AM, Stacey D, Légaré F. Coaching to support patients in making decisions. BMJ. 2008;336(7638):228-9.

10. Stacey D, Murray MA, Légaré F, Sandy D, Menard P, O'Connor A. Decision coaching to support shared decision making: a framework, evidence, and implications for nursing practice, education, and policy. Worldviews on EvidenceBased Nursing, 2008;5(1):25-35.

11. Joseph-Williams N, Edwards A, Elwyn G. Power imbalance prevents shared decision making. BMJ. 2014;348:93178.

12. Härter M, Moumjid N, Cornuz J, Elwyn G, van der Weijden T. Shared decision making in 2017: International accomplishments in policy, research and implementation. Z Evid Fortbild Qual Gesundhwes. 2017;123-124:1-5. 
13. Kasper J, Lager AR, Rumpsfeld M, Kienlin S, Smestad $\mathrm{KH}$, Brathen T, et al. Status report from Norway: Implementation of patient involvement in Norwegian health care. Z Evid Fortbild Qual Gesundhwes. 2017;123-124:75-80.

14. Légaré F, Adekpedjou R, Stacey D, Turcotte S, Kryworuchko J, Graham ID, et al. Interventions for increasing the use of shared decision making by healthcare professionals. Cochrane Database of Syst Rev. 2018; (7):CDoo6732.

15. Stacey D, Legare F, Lewis K, Barry MJ, Bennett CL, Eden $\mathrm{KB}$, et al. Decision aids for people facing health treatment or screening decisions. Cochrane Database of Syst Rev. 2017; (4):Cdoo1431.

16. Stacey D, Higuchi KA, Menard P, Davies B, Graham ID, $\mathrm{O}^{\prime}$ Connor AM. Integrating patient decision support in an undergraduate nursing curriculum: an implementation project. Int J Nurs Educ Scholarsh. 2009;6:artikkel 10.

17. Berger-Hoger B, Liethmann K, Muhlhauser I, Haastert B, Steckelberg A. Nurse-led coaching of shared decision-making for women with ductal carcinoma in situ in breast care centers: A cluster randomized controlled trial. Int J Nurs Stud. 2019;93:141-52.

18. Agoritsas T, Heen AF, Brandt L, Alonso-Coello P, Kristiansen A, Akl EA, et al. Decision aids that really promote shared decision making: the pace quickens. BMJ. 2015;350:g7624.

19. Eiring O, Nytroen K, Kienlin S, Khodambashi S, Nylenna $\mathrm{M}$. The development and feasibility of a personal healthoptimization system for people with bipolar disorder. BMC Med Inform Decis Mak. 2017;17(1):102.

20. Brembo E, Eide H, van Dulmen S, Kasper J. Building ground for didactics in a patient decision aid for hip osteoarthritis. Exploring patient-related barriers and facilitators towards shared decision-making. Patient Education and Counselling. 2020;103(7):1343-50.

21. Kienlin S, Nytrøen K, Stacey D, Kasper J. Ready for shared decision making: Pretesting a training module for health professionals on sharing decisions with their patients. Journal of Evaluation in Clinical Practice. 2020;26(2):610-21. 
22. Kienlin S, Kasper J, Liethmann K, Grafe A, Stacey D, Nytrøen K. Evaluation of an interprofessional training module in Shared Decision Making (Ready for SDM): a cluster randomized controlled trial. Quèbec: The 10th International shared decision making conference; 2019.

23. Kienlin S, Nytroen K, Kasper J, Stacey D. Shared decision-making supported by decision coaches - evaluation of a training module. Oslo: OCHER; 2020.

24. Geiger F, Liethmann K, Reitz D, Galalae R, Kasper J. Efficacy of the doktormitSDM training module in supporting shared decision making - Results from a multicenter doubleblind randomized controlled trial. Patient Educ Couns. 2017;100(12):2331-8.

25. Kienlin S, Poitras M-E, Stacey D, Nytroen K, Kaspe J. Ready for SDM - Evaluating a train-the-trainer program to facilitate implementation of SDM training in Norway. Til vurdering i BMC Medical Informatics \& Decision Making. 2020.

26. Bakke T, Udness E, Harboe I. Læringsnettverk som verkt $\varnothing$ y i kvalitetsforbedring - en oppsummering av forskning og erfaring. Oslo: Nasjonalt kunnskapssenter for helsetjenesten; 2011.

27. Lov 7. februar 1999 nr. 63 om pasient- og brukerrettigheter (pasient- og brukerrettighetsloven). Tilgjengelig fra: https://lovdata.no/dokument/NL/lov/1999-0702-63 (nedlastet 07.10.2020).

28. Meld. St. 11 (2018-2019). Kvalitet og pasientsikkerhet. Oslo: Helse- og omsorgsdepartementet; 2017. Tilgjengelig fra: https://www.regjeringen.no/no/dokumenter/meld.-st.-1120182019/id2622527/ (nedlastet 07.10.2020).

29. Meld. St. 28 (2014-2015). Legemiddelmeldingen - Riktig bruk - bedre helse. Oslo: Helse- og omsorgsdepartementet; 2015. Tilgjengelig fra: https://www.regjeringen.no/no/dokumenter/meld.-st.-2820142015/id2412810/ (nedlastet 07.10.2020).

30. Meld. St. 34 (2015-2016). Verdier i pasientens helsetjeneste - Melding om prioritering. Oslo: Helse- og omsorgsdepartementet; 2015. Tilgjengelig fra: https://www.regjeringen.no/no/dokumenter/meld.-st.-3420152016/id2502758/ (nedlastet 07.10.2020). 
31. Helse- og omsorgsdepartementet. Strategi for å øke helsekompetansen i befolkningen 2019-2023. Oslo: Helse- og omsorgsdepartementet; 2019. Tilgjengelig fra:

https://www.regjeringen.no/no/dokumenter/strategi-for-aoke-helsekompetansen-i-befolkningen-2019-2023/id2644707/ (nedlastet 07.10.2020).

32. Forskrift 15. mars 2019 nr. 412 om nasjonal retningslinje for sykepleierutdanning. Tilgjengelig fra:

https://lovdata.no/dokument/SF/forskrift/2019-03-15-412 (nedlastet 07.10.2020). 